\title{
MMA Associate Editor Elvin Beach Joins the Department of Materials Science and Engineering at The Ohio State University
}

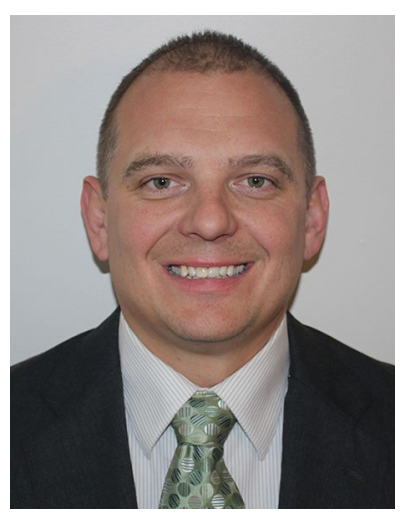

Dr. Elvin Beach, an associate editor for Metallography, Microstructure, and Analysis since 2013, has taken a position in the Department of Materials Science and Engineering at The Ohio State University as an Associate Professor of Practice in Materials Science and Engineering. Dr. Beach received his B.S. in metallurgical engineering and M.S. in materials science and engineering from Michigan Technological University and a Ph.D. in materials science and engineering from The Ohio State University. He has acquired extensive industrial experience at Dow Chemical, Owens-Corning, Battelle Memorial Institute, and Worthington Industries.

At Ohio State, Dr. Beach will coordinate laboratory staff support; ensure lab equipment is updated; and develop, implement, and enforce safety guidelines and procedures.
He will be leading new initiatives in laboratory instruction and class demonstrations, training teaching assistants who can support teaching of the labs, developing and implementing hands-on testing and characterization of materials, and coordinating undergraduate student employees to support the educational programs of the department. Maintaining scholarships in engineering education and outreach activities are also part of his role, in addition to overseeing the development and teaching of undergraduate course content.

Dr. Beach looks forward to working with students in a hands-on/lab/experimental class setting. He commented, "I really enjoy teaching how to do laboratory work and to work through problems and failures that inevitably arise. The most rewarding part of my former position was watching people grow and become confident in their lab work and results interpretations. I expect to find the same joy at Ohio State. I'm also looking forward to learning a lot from everyone. The staff, faculty, and students have a wealth of knowledge, and I look forward to learning from everyone's unique experiences and ideas."

In addition to serving as an associate editor for MMA, Dr. Beach is also an associate editor for ASM's Journal of Materials Engineering and Performance.

Publisher's Note Springer Nature remains neutral with regard to jurisdictional claims in published maps and institutional affiliations. 